\title{
Phonetic and phonological considerations on the moraic status of pre-NC vowels in Bemba
}

\author{
Silke Hamann \\ Amsterdam Center for Language and Communication, University of Amsterdam, The Netherlands \\ E-mail: silke.hamann@uva.nl \\ Nancy C. Kula \\ Department of Language and Linguistics, University of Essex, United Kingdom \\ Department of Linguistics and Language Practice, University of the Free State, South Africa* \\ E-mail: nckula@essex.ac.uk
}

\begin{abstract}
The pre-NC vowel in many Bantu languages is generally understood to be long. In Bemba, where there is also a vowel length contrast, this raises the question whether the pre-NC vowel is phonetically as long as lexical long vowels and how phonologised this length might be. In contrast to lexically long vowels, pre-NC vowel length is attributed to vowel lengthening resulting from the restructuring of a nasal to create a prenasalised stop. This is thus relevant to whether such stops are treated as unit segments or not. The present paper focuses on the pre-NC vowel and presents an evaluation of whether the pre-NC vowel is monomoraic or bimoraic by considering both phonetic and phonological evidence. Segmental and most tonal evidence leans towards a monomoraic treatment of the pre-NC vowel. One set of tonal data, however, shows variation in moraicity, presenting a mixed picture that we conclude emanates from the intermediate phonetic duration of the pre-NC vowel. ${ }^{1}$
\end{abstract}

Keywords: NC clusters; prenasalised stops; vowel lengthening; mora; homorganic clusters; Bantu languages

\section{Introduction}

Homorganic sequences of a nasal and an obstruent (henceforth, NC) are a common feature amongst Bantu languages. The vowels preceding these NC sequences are often longer than vowels that occur before single consonants, and a process of pre-NC vowel lengthening has been reported for many Bantu languages (see Miti 2006 for an overview). This process is

\footnotetext{
* The author is a Research Associate of the University of the Free State.

${ }^{1}$ This paper draws inspiration from Laura Downing's work on nasal-consonant segments and her meticulous evaluation of evidence. We hope to have followed similar scrutiny in analysing Bemba here, with a view to making generalisations for similarly structured Bantu languages. We hope Laura will enjoy the far from conclusive case we present here.
} 
independent of whether the homorganic NC sequence occurs morpheme-internally or across a morpheme boundary.

Pre-NC lengthening has been treated in the literature as a process of compensatory lengthening (e.g., de Chene and Anderson 1979, Kavitskaya 2002): the nasal vacates its mora position and this mora re-associates exclusively with the preceding vowel, which becomes long. The remaining NC can be interpreted as a complex single onset (e.g., by Clements 1986, Hyman 1992, Hubbard 1995), or as a consonant cluster (see Herbert 1975 and Maddieson 1993). In the present article, we are not concerned with this question.

Bantu languages with a vowel length contrast that is phonemic, typically neutralise their vowel contrast before NC sequences. However, the outcome of this neutralisation varies widely, as documented by Hubbard (1995). Figure 1 compares the duration of vowels before $\mathrm{NC}$ to that of short and long vowels in seven Bantu languages with a phonemic vowel length contrast, summarising the existing acoustic studies and complementing Hubbard's comparative study. At the top is Yao, a language in which pre-NC vowels are very similar in duration to the phonemically long vowels (therefore labelled [V:NC]), while at the bottom is Tonga, a language in which pre-NC vowels have a duration that is similar to that of the phonemically short vowels (labelled [VNC]). Chichewa also falls in the latter category (see the description by Downing and Mtenje 2017, supported by acoustic measurements in Hubbard 1994: 155).

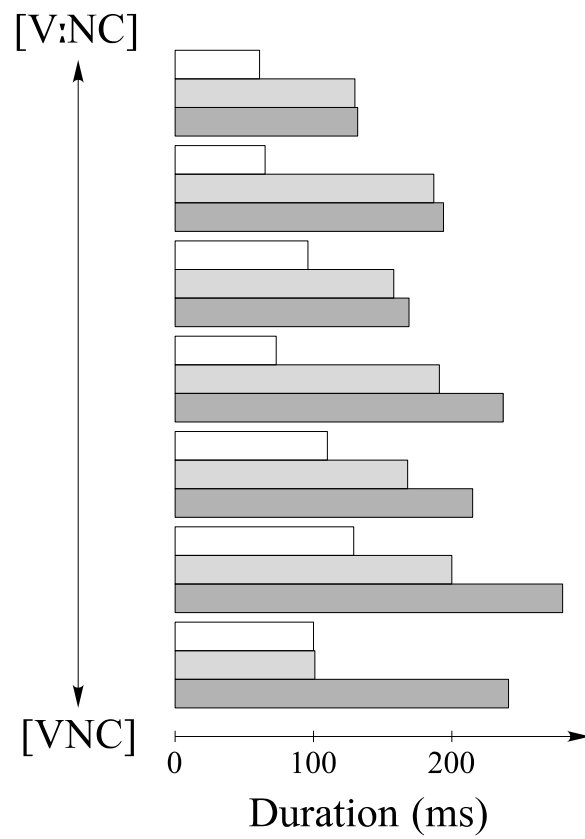

Yao (Hubbard 1995)

Lusaamia (Marlo \& Brown 2003)

Kinyarwanda (Myers 2005)

Luganda (Maddieson 1993, Vogel \& Spinu 2011)

Runyambo (Hubbard 1995)

Sukuma (Maddieson 1993)

Tonga (Hubbard 1995)

Figure 1. Degree of pre-NC vowel lengthening (in descending order) in Bantu languages with a phonemic vowel length contrast. White $=$ short vowel, light grey $=$ pre-NC vowel, dark grey $=$ long vowel

Interestingly, pre-NC lengthening also occurs outside the Bantu language family, though less frequently. Examples can be found in Johore Malay, the Bantoid language Noni (spoken in Cameroon), and Southern-Cushitic Iraqw (all three discussed in Downing 2005: 187-188). 
Riehl (2008) provides an experimental study on pre-NC lengthening in the Austronesian languages of Tamambo, Erromangan, Vanuatu, and Pamona.

Bemba, a central Bantu language (M42 in Guthrie's 1948 classification) spoken in Zambia and the Southern Democratic Republic of Congo (Mwansa 2018), has a phonemic vowel length contrast which is neutralised before NCs. The acoustic evidence given in Hamann and Kula (2015: 65-66) based on one speaker shows that this pre-NC vowel, though longer than the short vowel, is considerably shorter than a phonemically long vowel. This finding seems to contradict the general assumption that in Bemba the neutralisation in $\mathrm{NC}$ position results in a long vowel (see, e.g., Sharman 1963, Kula 2002).

The aim of the present study is twofold: in the first part, we provide an extension of our 2015 vowel duration measurement study to test whether the findings of a phonetically medium-long pre-NC vowel are generalisable to a larger group of Bemba speakers. The second part looks at the phonological status of these vowels, and brings together arguments from phonological considerations and a second phonetic study on the possible mono- or bimoraic nature of the pre-NC vowel. Earlier work by Hyman (1992), based on phonological evidence, has shown that Bemba presents a hybrid system where some evidence points towards a monomoraic analysis but other evidence, by contrast, points to a bimoraic analysis. We return to this finding in our discussion and demonstrate that, with additional phonological facts complemented by phonetic data, Bemba still shows an ambiguous position with respect to the moraic status of the pre-NC vowel.

\section{Acoustic measurements of vowel duration}

We begin by trying to establish whether there is a vowel duration difference between the pre-NC vowel and a regular long vowel. Thus, the duration of vowels before NCs were compared to the duration of phonemically short and long vowels before sonorants in monomorphemic, bisyllabic words. Bemba has five vowel qualities, /i e a o u/, with the mid vowels being lax. All five vowel qualities were included in the study. A word-list with near minimal-pairs was used to elicit the data consisting of 25 words, with a vowel length contrast before a lateral and before a nasal, given in (1a), and without contrast before NC, in (1b); note that the latter is transcribed with a long vowel, as is common for Bemba. The words were spoken in isolation and repeated five times by three native speakers of Copperbelt Bemba (two female, one male).

(1) a. Stimuli contrasting in vowel length before sonorants:

Before /l/

\begin{tabular}{lll} 
short & \multicolumn{3}{c}{ long } \\
lìlá 'cry' & tì:lá 'say' \\
pèlá & 'grind' & pé:lá 'give' \\
làlá 'crack' & pà:lá 'bless' \\
ßòlá 'rot' & ßò:lá 'bump/hit' \\
tùlá 'pierce' & tú:lá 'offer'
\end{tabular}

\section{Before /n/ or /m/}

$\begin{array}{llll}\text { short } & & \text { long } & \\ \text { míná } & \text { 'swallow' } & \text { nì:ná 'climb' } \\ \text { péná } & \text { 'be demented' } & \text { pè̀má 'breathe' } \\ \text { tàná 'deny' } & \text { ká:ná 'refuse' } \\ \text { móná 'see' } & \text { nò:ná 'sharpen' } \\ \text { túmá 'send' } & \text { sù:má 'leak' }\end{array}$


b. Stimuli before NC, without contrast in vowel length:

$\begin{array}{ll}\text { Jì:ngá } & \text { 'smear' } \\ \text { sè:ndá } & \text { 'take' } \\ \text { sà:ngá } & \text { 'find' } \\ \text { lò:ygá } & \text { 'pack' } \\ \text { sù:ntá } & \text { 'limp' }\end{array}$

The onset and offset of the vowel tokens were determined and annotated in Praat (Boersma and Weenink 2017) on the basis of changes in formant movements and amplitude in the spectrogram, and a change in wave patterns and amplitude in the sound wave.

The statistical analysis was carried out with a linear mixed-effects model in the program $\mathrm{R}$ (Bates et al. 2015). The statistical model featured the dependent variable duration and the predictor type, i.e., vowels appearing before an NC cluster (NC), a short or a long vowel, and vowel height, i.e., whether the vowel is high $(\mathrm{H})$ or non-high $(\mathrm{L})$. Contrasts were set accordingly (for type: $\mathrm{NC}=0$, short $=-0.5$, long $=+0.5$; short and long $=-1 / 3, \mathrm{NC}=2 / 3$; for vowel height: $\mathrm{H}$ $=+0.5, \mathrm{~L}=-0.5)$. The model also accounted for type and height as random slopes per speaker. The complete model is given in (2).

$$
\text { duration } \sim \text { type }+ \text { height }+(\text { type }+ \text { height } \mid \text { speaker })
$$

The overall duration of the three vowel types is given in Figure 2.

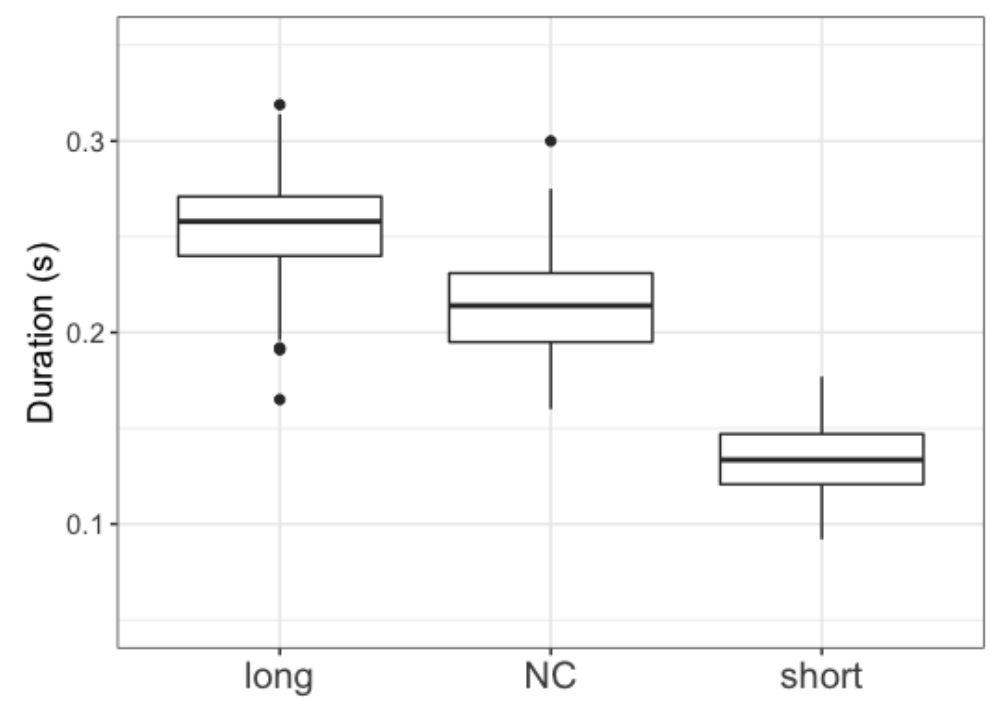

Figure 2. Duration of phonemically long vowels, pre-NC vowels, and phonemically short vowels

As is clear from Figure 2, pre-NC vowels are phonetically shorter, namely by $40.8 \mathrm{~ms}$, than underlying long vowels, and longer, namely by $80.59 \mathrm{~ms}$, than underlying short vowels. These differences are statistically significant $(p=0.0015)$. Figure 2 also shows that pre-NC vowels are longer than phonemically short vowels. Our results thus replicate the findings in Hamann and Kula (2015) that pre-NC vowels are of an intermediate duration, which is thus generalisable to a larger group of Bemba speakers. 
As is to be expected, the vowel duration is dependent on the height of the vowel, with high vowels being shorter than non-high vowels (by $21.3 \mathrm{~ms} ; p=0.0067$ ) - see Lindblom (1968) and Toivonen et al. (2015) for a cross-linguistic observation, and also Hamann, Miatto and Downing (2019) on the related Bantu language Tumbuka, and Myers (2005) on Kinyarwanda. Our vowel duration results, split by vowel height, are given in Figure 3.

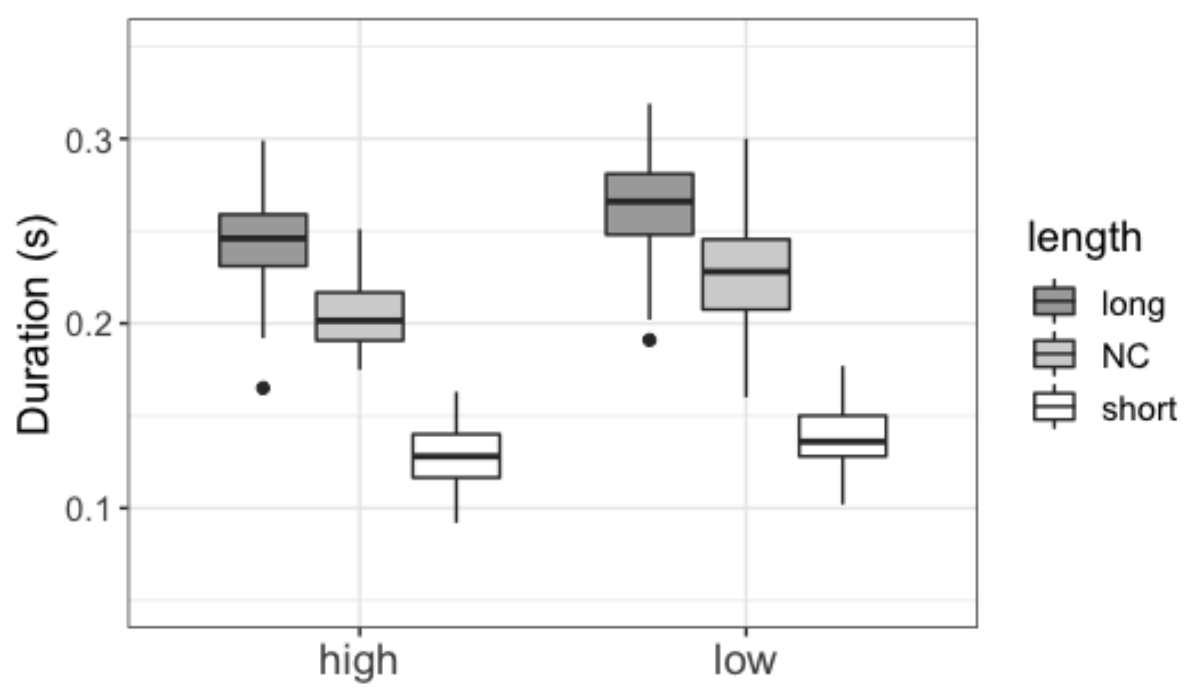

Figure 3. Duration of long, pre-NC and short vowels split by vowel height, where high = /i u/ and low $=/ \mathrm{a} \mathrm{e} \mathrm{o/}$

A reviewer pointed out to us that the place of articulation of the following nasals is not evenly distributed in our stimuli, and that place of articulation can have an influence on the duration of the preceding vowel. We therefore conducted a further analysis in which we looked at nasal place. Table 1 gives an overview of the average duration of the vowel by place of articulation of the following nasal, for simple nasals, and for NC sequences separately.

Table 1: Average duration (in seconds) of the vowel depending on the place of articulation (bilabial, alveolar, or velar) of the following nasal (simple nasal or NC sequence), where the simple nasals are further split by phonological vowel length

\begin{tabular}{|l|c|c|c|c|}
\hline \multicolumn{2}{|c|}{ Simple nasal } & Bilabial & Alveolar & Velar \\
\cline { 2 - 5 } & short V & 0.123 & 0.128 & - \\
\hline \multirow{2}{*}{ NC sequence } & long V & 0.234 & 0.252 & - \\
\hline
\end{tabular}

Velar place of articulation for simple nasals is extremely rare in Bemba, with only a few lexical items with a preceding short vowel and likely none with a preceding long vowel, accounting for the dashes in the last column of Table 1. Our results show that vowels preceding the simple nasals are slightly longer if the place of articulation is alveolar compared to bilabial. This difference is statistically not significant. For NC sequences, our stimuli accidentally did not contain bilabials, indicated by the dash in the last row of Table 1 . The vowels preceding alveolar NCs in our data have a mean duration of $199 \mathrm{~ms}$, while those preceding velar NCs have a mean duration of $227 \mathrm{~ms}$. This difference is statistically significant $(p=0.00108)$. Unfortunately, we could not include place of articulation as a predictor in a statistical model because of the skewedness of our data. 
Our phonetic study thus shows that, compared to phonemically long and short vowels, pre-NC vowels are, in durational terms, intermediate between the phonemic short and long vowels. This finding could be interpreted as evidence that the pre-NC vowel is not bimoraic in Bemba, since it is not as long as a phonemically long vowel. According to this interpretation, the lengthening of the pre-NC vowel could be purely phonetic: a language-specific enhancement of a coarticulatory effect caused by the slow lowering of the velum (see Hamann et al. 2019 who provide this argument to account for the very small but significant difference in Tumbuka between pre-NC vowels and vowels in other positions, where the latter are non-contrastive in length).

On the other hand, one could argue that the present finding does indeed provide evidence for the bimoraic status of the pre-NC vowel, because a second mora in this position does not necessarily have to be realised with the same phonetic duration as a second mora in a long vowel. Another difference between pre-NC and long vowels that could account for the observed durational difference is the fact that long vowels are underlyingly long, while pre-NC vowels derive their second mora through the phonological process of compensatory lengthening. Hence one could argue that derived long vowels are realised with a shorter duration than underlyingly long vowels. We will return to this point in the discussion.

To sum up our findings, the intermediate phonetic duration of pre-NC vowels in Bemba does not allow for a direct phonological interpretation.

\section{Phonological processes and the pre-NC vowel}

In this section, we turn to phonological arguments on the moraic status of the pre-NC vowel in Bemba. Hyman (1992), as noted in the introduction to this paper, concludes that Bemba presents conflicting evidence with regard to the moraic status of the pre-NC vowel. He proposes that only lexically long vowels count as bimoraic for mora-counting tone processes, while pre-NC vowels do not. For mora-counting prosodic morphological processes, on the other hand, pre-NC vowels count as bimoraic. In earlier work on Bemba, Kula $(1999,2002)$, working within a non-moraic framework, does not discuss the moraic status of the pre-NC vowel; rather, she focuses on the representation of NCs, arguing that these should be treated as sequences and not as arising from a prenasalisation process, which leads to a lexical treatment of the pre-NC vowel length.

In the following subsections, we consider four phonological processes in Bemba that provide some insight into the moraic status of the pre-NC vowel. We describe first the segmental processes of hiatus resolution ( $\$ 3.1)$ and reduplication $(\$ 3.2)$, and then the tonal processes of ternary spreading of high tone (\$3.3) and tone contrast (\$3.4) are considered, with a preliminary phonetic study accompanying the tone contrast discussion.

\subsection{Hiatus resolution}

In Bemba, two short vowels result in vowel fusion (Kashoki 1968: 25, Kula 2002: 54ff, Hamann and Kula 2015: 66), as the examples in (3a) and (3b) show. Identical as well as non-identical vowels undergo fusion. For contrasting vowels, the quality and order of the vowels involved is important in that total fusion only applies between /a/ and a following high vowel. In other cases, when the first vowel is high it turns into a glide, lengthening the remaining vowel. Fusion applies both within morphologically complex words, cf. (3a), and across word boundaries, cf. (3b). Data are drawn from Kula (2002: 56-57). 


\begin{tabular}{|c|c|c|}
\hline a. & $\begin{array}{l}\text { /à-lá-ìß-à/ } \\
\text { 3SG-HAB-steal-FV }\end{array}$ & $\begin{array}{l}\rightarrow \quad[\text { àlê: } \beta a ̀] \\
\text { 's/he steals' }\end{array}$ \\
\hline b. & $\begin{array}{l}\text { litfíkópó îfjî/ } \\
\text { 7tin 7DEM }\end{array}$ & $\begin{array}{l}\rightarrow \text { [îtfíkópwê:ţ̂̀] } \\
\text { 'this tin' }\end{array}$ \\
\hline c. & $\begin{array}{l}\text { /à-là:-ìs-à/ } \\
\text { 3sG-2FUT-come-FV }\end{array}$ & $\begin{array}{l}\rightarrow \quad \text { [àlà:ìsà] } \\
\text { 's/he will come' }\end{array}$ \\
\hline
\end{tabular}

Example (3c) shows that no hiatus resolution applies when a long vowel is followed by a short one. This could be argued to be avoidance of a three-mora merger, suggesting that the long vowel in this case has two moras. We noted in earlier work that there is no context where a short vowel is followed by a long one but the prediction would be that - on the same grounds as for the sequence of a long vowel plus a short one, namely avoidance of a three-mora merger - no vowel fusion should apply in such cases and hence no hiatus resolution.

The question of relevance to the present study is how pre-NC vowels behave with respect to hiatus resolution. Bickmore and Kula (2013: 111) provide the following example:

(4)
/ßá-ká-ímb-íl-à kó/
$\rightarrow \quad$ [ßákéémbílà kó]
2SM-3FUT-sing-APPL-FV 17LOC
'They will sing there (in that location)'

The example in (4) shows that a hiatus of the short vowel /a/ of the future marker plus the pre-NC vowel of the verb root is resolved by total vowel fusion. This is unexpected if the pre-NC vowel is long because, in this case, based on earlier patterns, we would predict avoidance of a three-mora merger. If, on the other hand, the pre-NC vowel is interpreted as short, then (4) would conform with the examples in (3a) and (3b) but contrast with (3c).

The process of hiatus resolution therefore provides evidence for an interpretation of pre-NC vowels as monomoraic, under the assumption that Bemba has a general avoidance of a three-mora merger.

\subsection{Reduplication}

Productive reduplication in Bemba generally involves total reduplication of the verb form. However, there are cases of partial reduplication where the meanings are generally lexicalised or depict onomatopoeic actions. Partial reduplication involves filling a CVCV reduplicant which can be achieved in different ways, as discussed in Kula (2002: 100) and as the examples in (5) show. If the stem is CV:-initial, the initial long vowel is part of the CV:-reduplicant - cf. (5a). If the verb consists of a short verb stem of one syllable, i.e., a $\mathrm{C}$ root $+\mathrm{FV}$, then this is doubled in the reduplicant $-\mathrm{cf}$. (5b).
(5) a. to:-to: $\int \mathrm{a}$
'whisper'
b. ljalja-lja
'eat here and there'

This can be considered in mora terms to mean that the reduplicant must include two moras which, in (5), are given by the long vowel or the doubled syllable. What we expect then with verb stems that consist of an $\mathrm{NC}$ with a long pre-NC vowel is that the reduplicant would be 
$\mathrm{CV}$ :, as this would satisfy the requirement for a bimoraic reduplicant. However, as the data in (6) show, the reduplicant is CV:N. Notice that the final nasal of the reduplicant CVN- becomes homorganic with the verb stem initial stop.

(6) a. tu:n-tu:mba

'carry a big load'

b. pu:m-pu:nta

'walk crookedly / stumble about'

If on the evidence of (5) we conclude that the reduplicant is bimoraic, then the data in (6) would suggest that the pre-NC long vowel is not treated as phonologically long with respect to reduplication, especially if we assume that the nasal is moraic, as these data would then also present cases of three-mora reduplicants. A possible alternative representation offered by a reviewer is that proposed by Morén and Zsiga (2006), where the vowel is simultaneously associated to its own mora and also to that of the following nasal. This would then account for the intermediate one-and-a-half length of the vowel and would offer an explanation for why pre-NC vowel length fails to be treated as phonologically long. Moraic nasals would, however, suggest that they should be tone bearing but nasals are never tone-bearing units in Bemba, and we would thus have to adopt an account where some moras are not tone-bearing units (see the discussion in section 4 for some options).

\subsection{Ternary high tone spreading}

Copperbelt Bemba has a process of ternary high tone (henceforth, $\mathrm{H}$ ) spreading, as discussed in Bickmore and Kula (2013). As the examples in (7) show, there is consistent ternary spreading in a sequence of three single-mora syllables, cf. (7a), and within two syllables when either the first (cf. (7b)) or the second (cf. (7c)) contains a long vowel. When the first vowel in the span is long, then $\mathrm{H}$ spreading only targets the first mora of a following long vowel, cf. (7c), or spreads only onto a following short vowel, cf. (7b). When the first two syllables are short and the third has a long vowel, then the long vowel shows a fall consistent with spreading only to the first mora to create a ternary span - cf. (7d). Here and in the following examples, the source of the $\mathrm{H}$ is underlined and the $\mathrm{H}$ span appears in bold.

(7) Spreading across three moras:
a. ßáá-ká-pát-à kó
2SM-3FUT-hate-FV 17 LOC
'they will hate as well'
b. tù-kà-léét-él-àn-à
1PL-3FUT-bring-APPL-RECIP-FV $1 \overline{7}_{\text {LOC }}$
'we will bring for each other'
c. tù-léé-lóòndòl-à kô
1PL-PROG-explain-FV 17LOC
'we are introducing'
d. $\quad$ a
2SM-3FUT-bury-FV 17LOC
'they will bury as well'


The example in (8) shows that $\mathrm{H}$ spreading does not extend to the final vowel of the verb stem if this is not phrase-final. This means that, in such cases, the ternary span cannot be realised, and the $\mathrm{H}$ spreads only once.

(8) No ternary spread to final vowel of verb stem:

$$
\begin{aligned}
& \text { tù-kà-láf-íl-à } \quad \text { kó } \\
& \text { 1PL-3FUT-hit-APPL-FV } 17 \text { LOC } \\
& \text { 'we will hit/throw (something) over there' }
\end{aligned}
$$

In addition to the above cases of ternary spreading, where the $\mathrm{H}$ spread spans three moras, there are also exceptional cases, as in (9) (from Bickmore and Kula 2013), where the spread extends to a fourth mora:

(9) Unexpected cases of spreading across four moras:
a. ßáá-lóóndólòl-é
2SM-explain-SUBJ
'let them introduce'
b. tù-kà-ßáá-lóóndólòl-à kó 1PL-3FUT-2OM-explain-FV 17LOC
'we will introduce them'
c. tù-kà-ßélééng-él-àn-à kó
1PL-3FUT-read-APPL-RECIP-FV $1710 \mathrm{C}$
'we will read for / on behalf of each other'

Bickmore and Kula (2013: 112) observe that spreading across four moras happens if the second mora is part of a long vowel, and in this case the $\mathrm{H}$ spreads into the next syllable. All examples provided by Bickmore and Kula (2013) involve a pre-NC vowel, which is assumed to consist of two moras. If one assumed that pre-NC vowels consisted of only one mora, they would not form exceptions to ternary spreading, but then their representation would be inconsistent with the long vowels in examples (7b-d), which are bimoraic with respect to their pattern of ternary spreading. If we accepted the difference in mora count as capturing the difference between lexical long vowels and pre-NC vowels, particularly in light of the Morén and Zsiga (2006) proposal for pre$\mathrm{NC}$ vowels being monomoraic, we expect the pre-NC vowel in $(7 \mathrm{c})$ to be monomoraic and the lexical long vowels in (7b) and (7d) to be bimoraic. The ternary spreading patterns support bimoraicity in lexical vowels but the pre-NC vowel does not behave as if it is monomoraic because there is fall in the $\mathrm{H}$ tone on the third syllable in (7c).

Kula and Bickmore (p.c.) provide examples of similar exceptional spreading that do not involve VNC but where the second vowel is long, as shown in (10). These all show unexpected spreading to four moras if we understand the long vowel to be bimoraic. Example (10a) involves a phonemically long vowel which, as was shown in section 2, would be phonetically long and thus expected to have two moras, and yet $\mathrm{H}$ spreading continues into the following vowel. Example (10b) is a long vowel derived from vowel fusion between the object marker -mu- and the initial vowel of the verb stem. With no changes in syllabic position, we would predict that this would 
contain two moras but here too the $\mathrm{H}$ spreads into the next syllable creating a larger than ternary span. Examples (10c-e) involve lexicalised reduplication where, based on mora count, we would expect a fall in the second long syllable but, unexpectedly, the whole second syllable is high.

(10) Further unexpected cases of spreading across four moras:
a. $\quad$ áá-Jík-íl-à bwì̀nò
2SM-bury-APPL-FV well
'they bury for someone well'
b. ßáá-mú-úm-ín-à bwì̀nò
2SM-3SG.OM-beat-APPL-FV well
'they beat for him well'

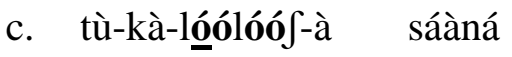
1PL-3FUT-nag-FV a.lot
'we will nag (someone) a lot'
d. ù-kà-tóótóóf-à $\quad$ sáàná
3SG.SM-3FUT-whisper-FV a.lot
'you will whisper a lot'
e. ù-kà-tóótóóf-éf-à Chisanga
3SG.SM-3FUT-whisper-APPL-FV Chisanga
'you will whisper to/for Chisanga'
f. $\beta \underline{a}$-ká-'tóòtòò $\int-\mathrm{è}-a ̀$ Chisanga
2SM-3FUT-whisper-APPL-FV Chisanga
'they will whisper to/for Chisanga'

Since lexical long vowels are unquestionably bimoraic, these examples would seem to suggest that $\mathrm{H}$ tone spread might not be based on the mora but on the syllable. In this case, all of the examples in (10), barring (10f), would be consistent with ternary spreading at the syllable level, keeping in mind that $(10 \mathrm{c}-\mathrm{d})$ would also consistently show no spreading to the final syllable, as these are non-phrase final forms (cf. (8)). (10e) shows that if another syllable intervenes, it gets high tone. (10f), however, as well as examples like [tù-léé-lóòndòl-à kó] in (7c) and [tù-kà-léétél-àn-à kó] in (7b), of which there are many, would always present counterexamples to a syllable-based analysis. We can only speculate that perhaps morphology/Tense-Aspect has a role to play in explaining these contrasting patterns.

With regard to the pre-NC vowels in (9), if a ternary $\mathrm{H}$ spreading analysis is to be maintained, then these vowels would have to be treated as monomoraic. These data are, however, also similarly at odds with those in (10), which contain lexical long vowels. Therefore, the ternary $\mathrm{H}$ spreading data are inconclusive with respect to the phonological status of the pre-NC vowel. 


\subsection{Tone contrast}

The second mora of a pre-NC vowel in Bemba has been argued to carry contrastive tone (Bickmore and Kula 2013, Breteler and Kager 2017), as illustrated by the examples in (11a) vs. (11b). Note that in the example in (11b), ternary spreading is blocked due to the presence of an underlying tone on the final vowel. ${ }^{2}$ In this subsection, the vowels of relevance (and not the $\mathrm{H}$ tone span as in the previous subsection) are given in boldface.
a. Bélééngèlá
'read for!'
/ßéleng-il-a $+\mathrm{HF} /$
b. Béléèngá
'read!' read-APPL-FV
/ßéleng-a $+\mathrm{HF} /$
read-FV

If the pre-NC vowel was monomoraic, then (11a) and (11b) would not have contrastive tone. We would expect outputs as in (12a) and (12b) below, respectively. The two forms would only differ in as far as (12b) would have a downstep triggered by the underlying/Melodic High tone on the final syllable, to avoid an OCP violation (see Kula and Hamann 2017: 325-326).

(12) Hypothetical forms of (11) with monomoraic pre-NC vowels:
a. ? ßéléngèlá
'read for!'
b. ? ßéléng'á
'read!'

What is interesting for the present study is the fact that under a monomoraic pre-NC vowel analysis, the word in (12b) should not differ in pitch contour from a word like (13), with a similar phonological make-up (i.e., a monomoraic vowel with $\mathrm{H}$ followed by another, downstepped $\mathrm{H}$ ) but with a single nasal rather than an NC in the relevant position.

\section{ßákóm!é}

'they should cut/chop'

/ $\beta$ á-kom-e $+\mathrm{HF} /$

2SM-chop-SUBJ

If $\mathrm{VNC}$ is assumed to be monomoraic, (12b) and (13) should have very similar pitch movements: a high tone on the pre-nasal/-NC vowel followed by a downstep, i.e., an abrupt change to a lower tone register towards the end of the vowel. The following nasal or NC sequence should be realised already on the lower register, as it belongs (at least partly, in the case of the NC) to the following downstepped syllable.

The tone contour of (12a), on the other hand, is expected to show a gradual, phonetic lowering of the pre-NC vowel, continuing throughout the $\mathrm{NC}$ sequence, from its high tone to the low tone of the following vowel. This expectation is based on the pitch curves in Kula and Hamann (2017) for two-vowel sequences with differing tones and intervening sonorant, where the whole sequence exhibits a gradual change from the first tone height to the height of the second tone.

\footnotetext{
${ }^{2}$ This final $\mathrm{H}$ is a Melodic High tone which is determined by the Tense-Aspect. It is indicated here in the underlying form, with HF meaning High Final. See Bickmore and Kula (2013) for the full set of Melodic High tones and corresponding Tense-Aspects in Bemba.
} 
We performed a small-scale experiment to check the tone contours of these three words. For this, we recorded two speakers of Bemba (one female, one male) who read out each of these words five to six times. Figures 4 and 5 below show the averaged pitch contours for the three words for Speakers 1 and 2, respectively. In these figures, the vowels in pre-NC position and the ones in pre-nasal position are normalised for duration and thus set to the same length - the same holds for the duration of the NC sequence and the nasal - in order to enable a better comparison. Before we have a closer look at the figures, we first report the actual durations of these segments, given in Table 2, and compare them to our results from section 2.

Table 2: Average duration (in seconds) of preceding vowel, NC sequence/nasal and following vowel split by speaker

\begin{tabular}{|c|c|c|c|c|}
\hline Speaker & Word & $\begin{array}{c}\text { Pre-NC/-nasal } \\
\text { vowel }\end{array}$ & NC/nasal & $\begin{array}{c}\text { Following } \\
\text { vowel }\end{array}$ \\
\hline \multirow{3}{*}{1} & ßákóm!é & 0.117 & 0.111 & 0.114 \\
\hline & ßéléng!á & 0.147 & 0.177 & 0.207 \\
\hline & ßéléngèlá & 0.123 & 0.135 & 0.127 \\
\hline \multirow{3}{*}{2} & ßákóm!é & 0.102 & 0.127 & 0.131 \\
\hline & ßéléng!á & 0.134 & 0.159 & 0.121 \\
\hline & ßéléngèlá & 0.116 & 0.114 & 0.103 \\
\hline
\end{tabular}

For both speakers, the pre-NC vowels in [ßéléng!á] and [ßéléngèlá] are longer than the pre-nasal vowel in [ßákóm!é], similar to our findings in section 2 . The pre-NC vowels in [ßéléngèlá] are slightly shorter than the ones in [ßéléng!á], which is attributable to the fact that the first word consists of four syllables and the second of three - an effect that can also be seen in the shorter duration of the NC sequence and the following vowel.

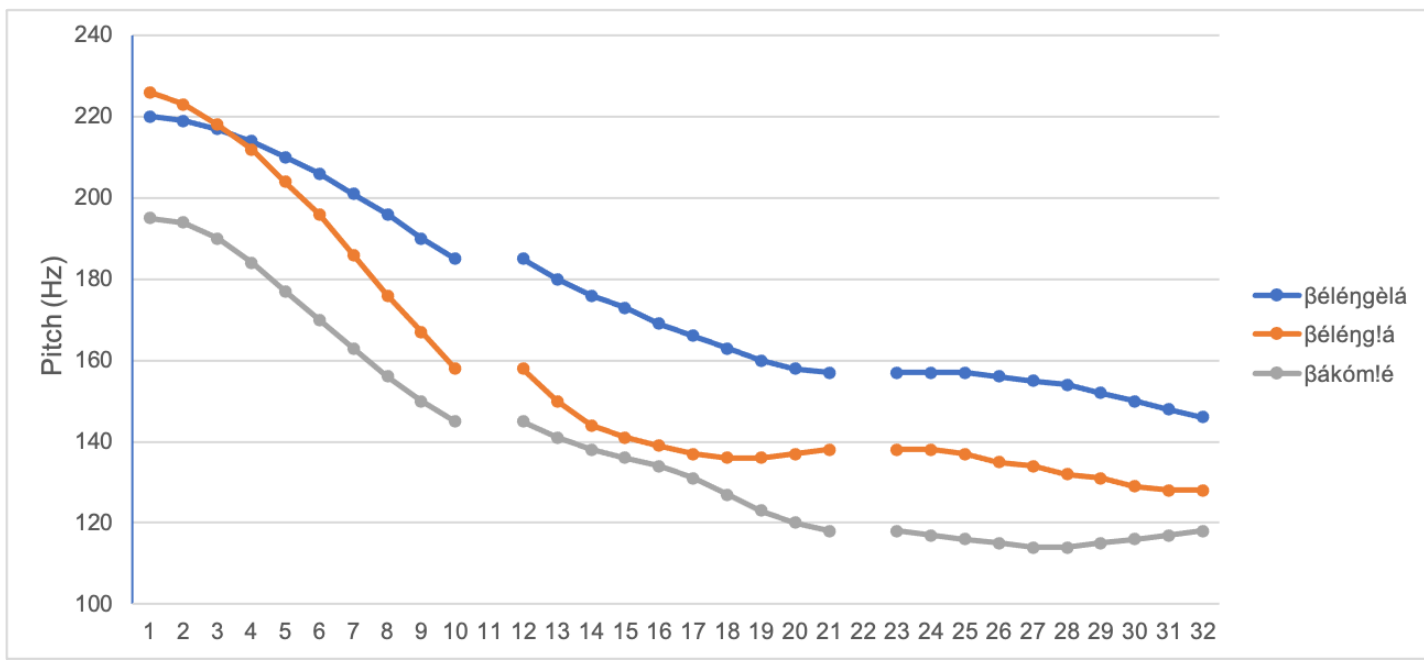

Figure 4. Time-normalised pitch contours for the averaged realisations of the three words by Speaker 1. Time points 1-10: vowel before NC/nasal; time points 12-21: NC sequence or single nasal; time points 23-32: following vowel

Let us now return to the pitch of the three words. As can be seen in Figure 4, Speaker 1 shows the difference in pitch contour between the realisation of the VNC sequence in [ßéléngèlá] (blue line) and [ßéléng!á] (orange line) that was predicted on the basis of a monomoraic analysis: 
both starting with a very similar pitch height, [ßéléngèlá] exhibits a gradual movement from a high pitch at the beginning of the first vowel towards a low pitch at the beginning of the second vowel, while [ßéléng!á] is realised with a more abrupt change from higher to lower pitch towards the end of the first vowel/beginning of the NC sequence, and a more steady-state realisation of pitch from the third time point of the $\mathrm{NC}$ sequence onwards, as expected due to a downstep. The pitch contour through the following vowel looks very similar in the two words, though that for [ßéléng!á] is approximately $20 \mathrm{~Hz}$ lower.

The pitch contour of [ßákóm!é] (grey line) in Figure 4 differs from the other two in being realised overall with a lower pitch, though the difference in height with [ßéléngèlá] (blue) increases towards the end of the first vowel: it is falling more steeply than [ßéléngèlá], as expected due to the downstep, and stays constant during the nasal. In both respects, it is similar to the pitch track of [ßéléng!á] (orange), supporting the monomoraic interpretation that [ßéléng!á] has a downstep on its last vowel. [ßákóm!é] and [ßéléng'á] differ in that the latter has an even steeper fall in the first vowel and a more steady-state stage in the following NC (though the difference in steepness might be partly due to time normalisation, as [ßákóm'é] has a shorter vowel than [ßéléng!á] - cf. Table 2).

Similar patterns are exhibited by the pitch contours of the three words produced by Speaker 2, given in Figure 5.

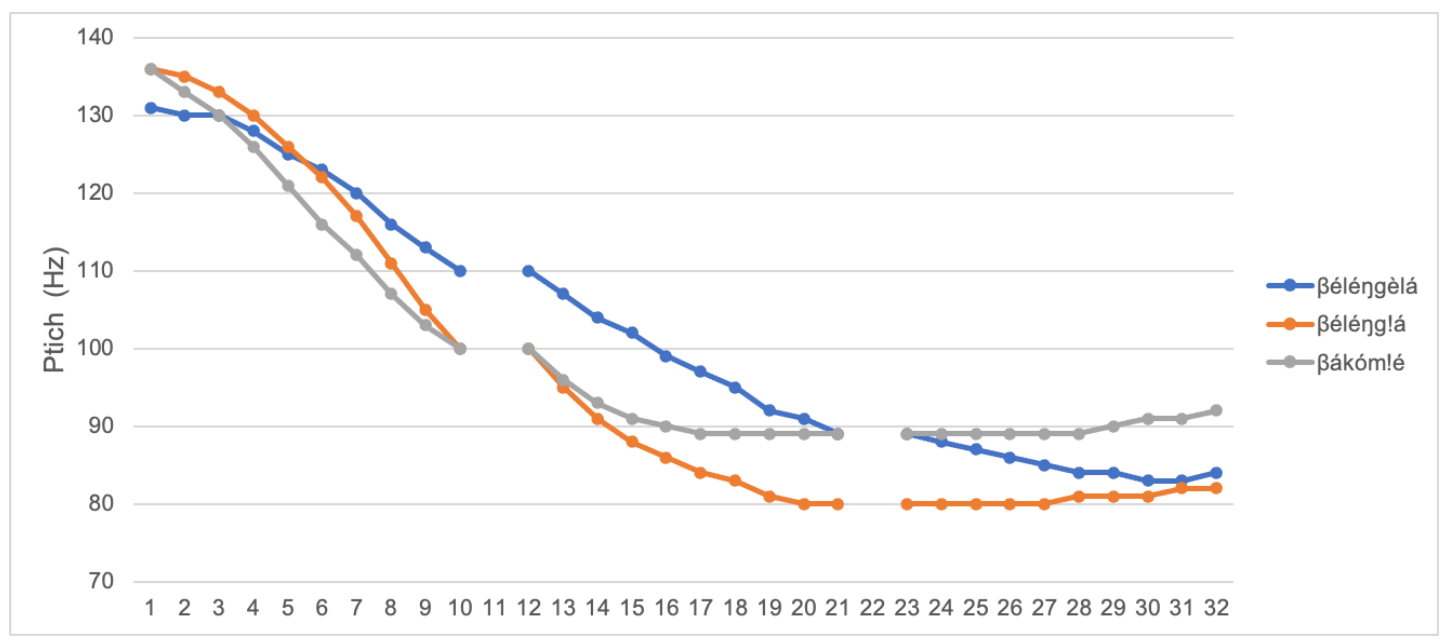

Figure 5. Time-normalised pitch contours for the averaged realisations of the three words by Speaker 2. Time points 1-10: vowel before NC/nasal; time points 12-21: NC sequence or single nasal; time points 23-32: following vowel

For the second speaker, all three words start off on a very similar pitch height. Both [ßéléng!á] (orange line) and [ßákóm'é] (grey line) show a steep fall in pitch on the first vowel, that continues into the beginning of the NC sequence/nasal. The pitch then stabilizes for both during the NC sequence/nasal and stays on the same level during the following vowel (though the steady pitch in [ßéléng!á] is $10 \mathrm{~Hz}$ higher than that in [ßákóm!é]). This contrasts with the pitch track of [ßéléygèlá] (blue line) which is less steep and shows a gradual decline from pre-NC vowel throughout the $\mathrm{NC}$ sequence that continues until the end of the following vowel.

These observations correspond nicely to the contrast between downstepped [ßéléng!á] and [ßákóm'é], on the one hand, and non-downstepped [ßéléngèlá], on the other, that we predicted 
on the basis of a monomoraic analysis of the two pre-NC words. However, phonetic evidence for a tone contrast on the pre-NC vowel that is predicted by a bimoraic analysis, with [ßéléèngá] (orange line) showing a falling tone and [ßélééngèlá] (blue line) a high tone, is more difficult to detect in the pitch tracks of the two speakers. Our phonetic measurements are thus more in line with the predictions of the monomoraic analysis of pre-NC vowels in as far as [ßéléng!á] and [ßákóm!é] pattern together.

\section{Discussion}

The present study collected potential evidence from phonetics and phonology for the moraic representation of pre-NC vowels in Bemba. In our phonetic study on vowel duration in section 2 , we found that the pre-NC vowels are of intermediate duration between short and long vowels. This finding does not allow us a straightforward phonological interpretation, compared to languages such as Yao and Lusaamia (cf. Figure 1 in the introduction), in which pre-NC vowels are as long as phonemically long vowels, or languages such as Tonga (ibid.), where pre-NC vowels are as short as phonemically short vowels.

The phonological processes in section 3 partly yielded inconclusive results as the phonological process of ternary $\mathrm{H}$ spreading, discussed in section 3.3, does not provide direct evidence for either a mono- or a bimoraic representation: ternary $\mathrm{H}$ spreading in Bemba turns out to be a complex process that cannot be fully accounted for by either a moraic analysis or an account in terms of syllables.

The remaining phonological processes, however, favour a monomoraic representation of the pre-NC vowel. Hiatus resolution, discussed in section 3.1, pointed in the direction of pre-NC vowels being monomoraic if one assumes a general avoidance of three-mora merger in Bemba. A monomoraic analysis is also the result of our discussion of reduplication in section 3.2. And lastly, the tone contrast in VNC sequences - the topic of section 3.4 - is also compatible with a monomoraic status of pre-NC vowels in Bemba.

Hyman (1992), focusing on the moraic status of the nasal in an NC finds similar mora mismatches in Runyambo and Haya that contrast between tone and morphology (reduplication and suffix allomorphy): tone treats the nasal in an $\mathrm{NC}$ as non-moraic but morphology treats it as moraic. One solution Hyman proposes, also based on mora mismatches in Bemba, is to consider differentiating tonal moras from quantity moras and possibly representing these on different tiers. But, as he argues, this would entail treating nasals as non-moraic, which does not hold in Runyambo and Haya. The final solution Hyman proposes is that the nasal has a mora but that, while all moras contribute to weight, only some count as tone-bearing units. Thus, in Luganda, although the nasal is mora bearing, it is not a tone-bearing unit.

While the focus here has not been on the moraic status of the nasal but rather the pre-NC vowel, we see an important similarity with Hyman's findings in that there is a contrast between the phonological tonal evidence (ternary spreading) and the segmental phonological evidence (reduplication and hiatus resolution) and tone contrast. While the segmental processes and tone contrast are more consistent with a monomoraic analysis of the pre-NC vowel, the tonal evidence from ternary spreading fluctuates between being moraic or bimoraic. 
The monomoraic patterning of the segmental processes suggests that the lengthening in the pre-NC vowel is phonetic and is not phonologised, presenting a case of "phonetics-phonology mismatch" as discussed, for example, in Hamann (2014). This would be consistent with the intermediate length of these vowels. We could then generalise that systems of intermediate vowel length of the pre-NC vowel are likely the ones that show mixed results with respect to being phonologically treated as mono- or bimoraic. This is supported by Hyman's (1992) findings where we see that Luganda and Runyambo - which, based on Figure 1 in section 1, have intermediate length - both show variation in mora count of the VN in the VNC contexts. We would predict the same for Sukuma. We speculate that the variation we see in the data for ternary spreading in Bemba with respect to the moraicity of the pre-NC vowel could be an indication of the intermediate vowel duration beginning to be phonologised.

\section{Concluding remarks}

Our investigation of the moraic status of the pre-NC vowel in Bemba has yielded contrasting evidence, but is strongly skewed towards the vowel being monomoraic based on both phonological - hiatus resolution and reduplication - and phonetic evidence with respect to tone contrast. The case that shows variation in moraicity is ternary $\mathrm{H}$ spreading and we have treated this as perhaps being the first signs of phonologisation of an initially phonetic length contrast. We consider the intermediate/half-long duration of the pre-NC vowel as the source of this variation, which results in a mismatch between phonetics and phonology.

Several issues were not part of the discussion in this paper or were only raised briefly and would need to be addressed in future studies. An important issue is that the present study focused solely on the phonological representation of vowels in pre-NC position and neglected the status of the nasal in VNC sequences in terms of whether it carries a mora or not (but see Downing 2005 for some detailed discussion). Nasals are never tone bearing in Bemba, suggesting that they may not be moraic, but to further investigate the nasal in the NC, a future phonetic study could compare the duration of the nasal in a VNC sequence to that of a single intervocalic nasal. Such a study could provide possible evidence on the moraic status of the nasal and hence also shed light on the moraic status of the pre-NC vowel: if the NC sequence turns out to be significantly longer than single nasals, this would speak against the assumption that the nasal in an NC sequence re-associates its mora with the preceding vowel, as proposed by Clements (1986) and discussed in section 3.2 above from Morén and Zsiga (2006).

Another issue is to do with the derived status of the pre-NC vowel, discussed in section 2 . There we suggest that the phonological difference between long vowels, which are underlyingly long, and pre-NC vowels, which are derived as the result of compensatory lengthening, could account for the durational difference that we found between the two. It would thus be interesting to systematically check if other cases of compensatory lengthening also produce phonetically half-long vowels, e.g., in gliding such as /mu+ana/ [mwa:na] 'child' (or penultimate lengthening for languages that have this). As we already saw, cases of vowel fusion/coalescence result in phonologically long vowels that are bimoraic. We would hope to tackle some of these issues in future work. 


\section{Acknowledgements}

We thank the Bemba speaker consultants for their participation and Stephen Nichols for his help in finding and recording speakers. Parts of this work were presented at the Bantu and Khoisan Lab Phonology workshop of the 20th International Conference of Linguistics that took place in Cape Town on 4 July 2018. We thank the audience and the organizers for the fruitful discussion. We also thank Paul Boersma for advice on the statistical analysis and Lee Bickmore for the discussion on some of the finer points of the tone data. All errors and any misrepresentations are our own.

\section{References}

Bates, D., M. Mächler, B. Bolker and S. Walker. 2015. Fitting linear mixed-effects models using lme4. Journal of Statistical Software 67(1): 1-48. https://doi.org/10.18637/jss.v067.i01

Bickmore, L. and N.C. Kula. 2013. Ternary spreading and the OCP in Copperbelt Bemba. Studies in African Linguistics 42(2): 101-132.

Boersma, P. and D. Weenink. 2017. Praat: Doing phonetics by computer. Computer program, version 6.0.2. Available online: www.praat.org (Accessed in December 2017).

Breteler, J. and R. Kager. 2017. Layered feet laid bare in Copperbelt Bemba. Proceedings of the 2016 Annual Meeting on Phonology. https://doi.org/10.3765/amp.v4i0.4003

Clements, G.N. 1986. Compensatory lengthening and consonant gemination in LuGanda. In L. Wetzels and E. Sezer (eds.) Studies in compensatory lengthening. Dordrecht: Foris. pp. 37-77. https://doi.org/10.1515/9783110821666-004

De Chene, B. and S.R. Anderson. 1979. Compensatory lengthening. Language 55: 505-535. https://doi.org/10.2307/413316

Downing, L.J. 2005. On the ambiguous segmental status of nasals in homorganic NC sequences. In M. van Oostendorp and J. van de Weijer (eds.) The internal organization of phonological segments. Berlin: De Gruyter. pp. 183-216. https://doi.org/10.1515/9783110890402.183

Downing, L.J. and A. Mtenje. 2017. The phonology of Chichewa. Oxford: Oxford University Press. https://doi.org/10.1093/oso/9780198724742.001.0001

Guthrie, M. 1948. The classification of the Bantu languages. London: Oxford University Press.

Hamann, S. 2014. Mismatches between phonology and phonetics. Keynote address presented at the 11th Old World Conference in Phonology, 25 January 2014, Leiden. Available online: https://www.fon.hum.uva.nl/silke/handouts/ocp11.pdf (Accessed 1 July 2021).

Hamann, S. and N.C. Kula. 2015. Bemba. Journal of the International Phonetic Association 45(1): 61-69. https://doi.org/10.1017/s0025100314000371 
Hamann, S., V. Miatto and L.J. Downing. 2019. Duration of vowels before homorganic nasalobstruent sequences in Tumbuka. In. S. Calhoun, P. Escudero, M. Tabain and P. Warren (eds.) Proceedings of the 19th International Congress of Phonetic Sciences. Canberra: Australasian Speech Science and Technology Association Inc. pp. 3568-3572.

Herbert, R.K. 1975. Reanalyzing prenasalized consonants. Studies in African Linguistics 6(2): 105-123.

Hubbard, K. 1994. Duration in Moraic Theory. Unpublished doctoral dissertation, University of California, Berkeley.

Hubbard, K. 1995. Prenasalised consonants and syllable timing: Evidence from Runyambo and Luganda. Phonology 12(2): 235-256. https://doi.org/10.1017/s0952675700002487

Hyman, L.M. 1992. Moraic mismatches in Bantu. Phonology 9: 255-265. https://doi.org/10.1017/s0952675700001603

Kashoki, M.E. 1968. A phonemic analysis of Bemba. Manchester: Manchester University Press.

Kavitskaya, D. 2002. Compensatory lengthening: Phonetics, phonology, diachrony. New York: Routledge.

Kula, N.C. 1999. On the representation of NC clusters in Bemba. Linguistics in the Netherlands 16 (1999): 135-148. https://doi.org/10.1075/avt.16.13kul

Kula, N.C. 2002. The phonology of verbal derivation in Bemba. Unpublished doctoral dissertation, Leiden University.

Kula, N.C. and S. Hamann. 2017. Intonation in Bemba. In L.J. Downing and A. Rialland (eds.) Intonation in African tone languages. Berlin: Mouton de Gruyter. pp. 321-364. https://doi.org/10.1515/9783110503524-010

Lindblom, B. 1968. Vowel duration and a model of lip mandible coordination. Speech Transmission Laboratory - Quarterly Progress and Status Report 8(4): 1-29.

Maddieson, I. 1993. Splitting the mora. UCLA Working Papers in Phonetics 83: 9-18.

Miti, L.M. 2006. Comparative Bantu phonology and morphology: A study of the sound systems and word structure of the indigenous languages of southern Africa. Cape Town: Centre for Advanced Studies of African Society (CASAS).

Morén, B. and E. Zsiga. 2006. The lexical and post-lexical phonology of Thai tones. Natural Language and Linguistic Theory 24: 113-178. https://doi.org/10.1007/s11049-004-5454-y

Mwansa, J.M. 2018. Bemba. In T. Kamusella, and F. Ndhlovu (eds.) The social and political history of southern Africa's language. London: Palgrave MacMillan. pp. 31-49. https://doi.org/10.1057/978-1-137-01593-8_3 
Myers, S. 2005. Vowel duration and neutralization of vowel length contrasts in Kinyarwanda. Journal of Phonetics 33(4): 427-446. https://doi.org/10.1016/j.wocn.2005.02.002

Riehl, A. 2008. The Phonology and Phonetics of Nasal-Obstruent Sequences. Unpublished doctoral dissertation, Cornell University.

Sharman, J.C. 1963. Morphology, Morphophonology and Meaning in the Single Word Verb Forms in Bemba. Unpublished doctoral dissertation, University of South Africa.

Toivonen, I., L. Blumenfeld, A. Gormley, L. Hoiting, J. Logan, N. Ramlakhan and A. Stone. 2015. Vowel height and duration. In U. Steindl, T. Borer, H. Fang, A. Garcia Pardo, P. Guekguezian, B. Hsu, C. O'Hara and I.C. Ouyang (eds.) Proceedings of the 32nd West Coast Conference on Formal Linguistics. Somerville, MA: Cascadilla Press. pp. 64-71. 